\title{
GRAMÁTICA, «EXCEPCIÓN», NORMA Y USO: A PROPÓSITO DE LA CONSTRUCCIÓN MÁS MAYOR. ASPECTOS SINCRÓNICOS Y DIACRÓNICOS (II)
}

\author{
Ana María Vigara TAuste \\ Universidad Complutense de Madrid
}

\begin{abstract}
RESUMEN
Esta segunda parte es continuación de lo publicado en el número anterior de la RSEL. El adjetivo mayor comparte con menor, mejor y peor una triple excepcionalidad: su formación irregular en latín (por supleción), su supervivencia en romance y su valor comparativo en un estado de lengua en el que, salvo precisamente en su caso, la comparación se expresa mediante construcción sintáctica analítica (más... que; menos... que; tan[to]... como, igual de... que). Clasificado mayor como adjetivo comparativo de grande con la ayuda del latín y los diccionarios de español, el juicio normativo se aplica a la corrección de la construcción más mayor (comparación redundantemente comparada de grande), sin tener en cuenta el significado temporal de la expresión (edad, paso del tiempo y sus efectos), con el que se generaliza en España y se conoce (y se usa en parte) en Hispanoamérica. Con tal significado, mayor puede, en el uso discursivo actual, funcionar como adjetivo positivo (de carácter gradativo y acumulativo) y, como tal, crear superlativos (mayorcísimo, muy mayor) y formar parte de estructuras comparativas como más mayor. La amnistía normativa oficial que el Diccionario panhispánico de dudas concede, inesperadamente, en 2005 a la construcción añade a su excepcionalidad gramatical (y semántica) una excepcionalidad más: la de su reconocimiento como adjetivo positivo (lexicalizado).
\end{abstract}

Palabras clave: adjetivo mayor, más mayor, comparación; adjetivos gradativos de edad; excepción gramatical.

\section{ABSTRACT}

This paper is the second part whose first part appeared in the previous issue of RSEL. The adjective mayor shares with menor, mejor and peor three exceptions: its irregular formation in Latin (by suppletion), its survival in Romance and its comparative value in a state of language in which -except in these cases-, comparison is expressed through an analytic construction (más... que; menos... que; tan[to]... como, igual de... que). Once that mayor is classified as a comparative adjective of grande (with the help of Latin, the dictionaries of Spanish), the normative judgement is applied to correct the construction más mayor (a redundant compared comparison of grande), without taking into account the temporal meaning of the expression (age, the passing of time and its effects), the meaning with which the adjective is generally used in Spain and also known (and partly used) in Latin America. In the current use of discourse 
and with this meaning, mayor may act as a positive adjective (with a gradable and accumulative character) and, therefore, create superlatives (mayorcisimo, muy mayor) and be part of comparative structures such as más mayor. In 2005, the Diccionario panhispánico de dudas surprisingly offers an official normative amnesty to the construction and adds to its grammatical and semantical exceptions a third one: its status as a positive (lexicalized) adjective.

Key Words: adjective mayor, más mayor, comparison; age adjectives; grammatical exception.

RECIBIDO: 27/12/2009

APROBADO: $17 / 05 / 2010$

\section{Del ROMANCE AL ESPAÑOL}

La alianza «natural» de nuestras gramáticas, diccionarios y obras normativas ha contribuido decisivamente, sin duda, a dificultar la percepción y el estudio del fenómeno y, por añadidura, de la construcción que nos ocupa (más mayor). Y muy especialmente, quizá, esa persistencia en clasificar mayor como adjetivo comparativo de grande ( «mayor = más grande»), para cuyo origen se remitía en los diccionarios al lat. grandis, pero también (sorprendentemente, tratándose de etimología) a magnus. De hecho, aunque ya en el Tesoro de la lengua castellana o española (Sebastián de Covarrubias 1611) se decía (s.v. «mayor»):

Del nombre latino maior, que algunas vezes sinifica anciano; su correlativo es menor,

ni mayor ni grande tuvieron acepción relacionada directamente con la edad (o el paso del tiempo) hasta 1984:

mayor. Dícese de la persona que excede en edad a otra (Usual, 1984)

Dícese de la persona entrada en años, de edad avanzada. V. hombre, señor, señora mayor (Manual 1984, hasta hoy).

grande. Dícese de la persona de edad avanzada (Usual 1984; no especifica dónde).

Así las cosas, era «normal» que las gramáticas persistieran en el valor comparativo de mayor y que las obras normativas -salvo excepcionesse afanaran en impedir la presencia de la expresión incorrecta más mayor entre nosotros. Lo era, al menos, si no reparamos en la contradicción de que hace ya mucho tiempo que la relación semántica entre los términos grande y mayor ha dejado de ser transparente para los hablantes de español, quienes raramente dirían, por ejemplo (pese a las gramáticas escolares que en muchos casos les ha tocado estudiar), 
que una mesa es «mayor» que otra, y preferirían decir que es «más grande» o «mucho más grande»; y en ningún caso se les ocurriría juzgar que una tercera mesa, en el ejemplo, es aún «más mayor» que la segunda (que era ya más grande que la primera). Sí dirían, en cambio, que la opacidad entre ambos términos es mayor (porque «opacidad» es sustantivo abstracto) todavía si encontramos este adjetivo en la estructura más mayor no referido al tamaño (ni a la importancia), sino a la edad, el tiempo o los efectos del paso del tiempo, como en el caso que nos interesa aquí.

\subsection{La lexicalización de mayor como adjetivo positivo y su especialización en el campo semántico «edad/paso del tiempo y sus efectos»}

Pese a que no está claro cómo se llegó realmente del latín maior 'adjetivo comparativo de magnus' al español mayor 'adjetivo comparativo de grande', ni cómo se dio el paso desde la dimensión «espacial» de grandis, magnus y maior a la dimensión «temporal» de mayor y más mayor, que es la que prevalece actualmente, la lexicalización de mayor como adjetivo positivo de valor temporal parece, si nos atenemos a las pruebas lingüísticas, un hecho irrefutable:

(26) Es mayorcísimo para ti y demasiado mayor para ella.

(27) -Yo ya soy mayor [y ya puedo beber coca-cola], ¿a que sí, mamá? -Sí, cariño, ya eres muy mayor, pero cuando seas más mayor aún. Mira, hay zumito de manzana...

(28) Y en [el mitin X], Rafael Simancas defendía su propuesta de transporte público / para jóvenes y más mayores... ['jubilados', en esta noticia] (Radio, Onda Cero, 15 octubre 2003).

(29) Un señor llega al Centro de Mayores y se dirige a una mesa en que hay otros cuatro señores jugando la partida:

- ¡Hombre!, el más joven..., dispuesto a perder... ¿Pero cómo se te ocurre jugar con este compañero?

-No, el menos mayor [de todos los mayores que estamos jugando]. $\mathrm{Y}$ vamos ganando. De momento. Vamos ganando de momeeento...

(30) Mi hermana es mucho mayor que yo: me lleva siete años. Lili tiene un año menos [que mi hermana], y Alberto es dos años más mayor. Alberto es el más mayor del grupo.

(31) [Con 56 años murió un hermano de Cristóbal Colón] Más mayor y con más achaques murió su tío Diego (TV-A3, TD, 7 junio 2003).

(32) Tiene 31 años, pero aparentemente parece mucho más mayor... (Director General de la Policía, TV1, TD, 28 diciembre 2002). 
Como adjetivo positivo, mayor -puede comprobarse en los ejemplosadmite intensificación (con muy y otros adverbios), superlación absoluta y relativa (mayorcísimo; el más mayor, el menos mayor), y gradación comparativa (tan/más/[menos] mayor), tanto cuando se usa con valor temporal objetivo (de [más] edad) como cuando se usa con valor temporal subjetivo (eufemismo para viejo, 'afectado por síntomas/efectos del paso del tiempo', otros valores).

Aunque actúe claramente como positivo, mayor conserva no obstante, inevitablemente, como adjetivo gradativo de la serie «edad» (pequeño, joven, maduro, viejo...), un cierto valor comparativo (original) o «cuantitativo» (cf. Lamíquiz 1991). Y esta ha sido seguramente la base de su éxito: la alta rentabilidad que su presencia ha aportado al paradigma.

Mayor actúa dentro de la serie de adjetivos referidos a «edad»/ "paso del tiempo y sus efectos» con valor acumulativo y puede, por eso, aparecer en cualquier punto del eje temporal ( $\mathrm{T}$ : tiempo cronológico «real») -excepto en el primero, claro está-. Mayor se refiere siempre a un estadio superior a otro cualquiera anterior (expresado, pensado, sentido o dado por el contexto), bien en el eje general $\mathrm{T}$ o bien en el interior de cualquiera de las subescalas que lo integran. Podemos representarlo en la siguiente figura (que corresponde con bastante rigor al uso temporal «objetivo»: 'de más edad'; pero precisaría matizaciones si quisiéramos aplicarlo al subjetivo-valorativo):

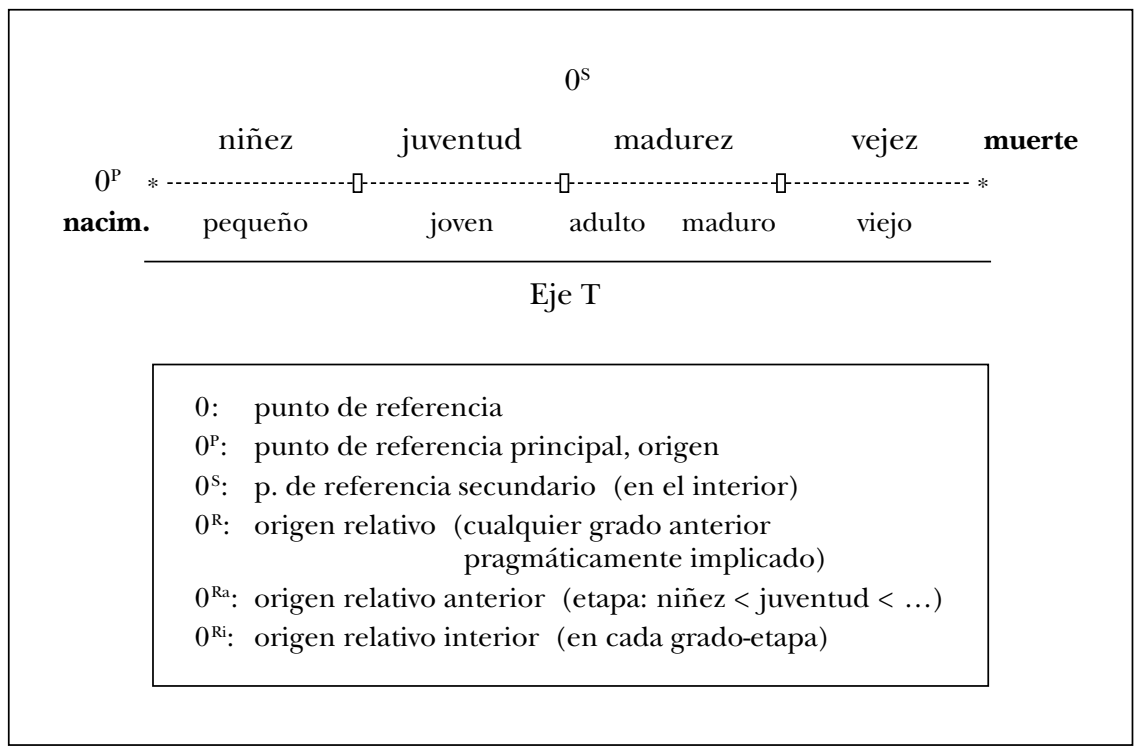

Imagen 1: Mayor, adjetivo gradativo de la serie 'edad, paso del tiempo y sus efectos'. 
Dicho sencillamente: todo el mundo es hoy mayor que ayer, ahora que hace un rato..., puede ser/parecer/sentirse (siempre) mayor de lo que es/se siente/se considera...; si es joven, es mayor que si es niño, y si es adulto es mayor que si es joven, etc.; y, en (el interior de) cada subescala o tramo, se puede ser mayor que otro miembro cualquiera, mayor que antes o incluso «el mayor»...

Se entiende, así, que la aparición de más mayor (en la comparación de superioridad o en el superlativo relativo) implica la adscripción (subjetiva) al grupo de los «mayores», que en el eje general lineal T serán «los más ancianos», como en

(33) [Ir el día de Todos los Santos al cementerio] una tradición que se mantiene, sobre todo, entre las personas más mayores (TV-A3, TD $15 \mathrm{~h}$, 1 nov. 2003),

pero también, sucesivamente, los «viejos» respecto de los «maduros»y estos respecto de los «jóvenes», etc.:

(34) ¿Sabes por qué? Porque de chicos recordamos cosas [...]; cuando de más mayor a lo mejor queremos recordar cosas, y no podemos (Iñaki Gabilondo, TV-C+, «Lo más plus», 12-7-2004);

y lo mismo se puede decir para el interior de cada tramo:

(35) Julia es de febrero, pero no es de las más mayores de su clase [porque en su clase hay muchos chicos que cumplen los años antes que ella].

(36) Ya más mayorcitos, con nueve meses, se les empieza a dar leche mineral [a los elefantitos] (Documental, TV2, 1 mayo 2007, 17 h).

Explica Ignacio Bosque en su trabajo «Usos figurados de los adjetivos que denotan dimensiones físicas» (1985, p. 64) que en las distintas series de este tipo de adjetivos hay siempre uno que acaba funcionando como término no marcado; es decir, que abarca todos los grados de una propiedad y muestra una gran capacidad de adaptación deíctica-subjetiva en la situación concreta de comunicación (en el discurso). En la serie diminuto-pequeño-grande-enorme, el término no marcado es grande, que es el que nos permite preguntar «¿cómo es de grande?» y obtener cualquier respuesta: «es pequeño/muy pequeño/diminuto/bastante grande/muy grande/enorme...». Y mayor, que durante tanto tiempo se ha descrito exclusivamente como adjetivo comparativo de grande (ignorando su significado «temporal» en la realidad del uso), ha asumido este papel (y con las ventajas, al menos en el español de España, del eufemismo) en la serie de adjetivos y sustantivos con valor adjetival de «edad, paso del tiempo y sus efectos»: el de término no marcado. Con él podemos preguntar «¿cómo es/se siente de mayor?» y podemos obtener cualquier respuesta en cualquier punto de la escala: «es muy joven», «tiene solo 
14 años», «de mediana edad», «viejo, muy viejo, octogenario»... Todos los demás miembros de su serie (niño-adolescente-joven-adulto-maduroviejo-anciano...) funcionarían de hecho seguramente como términos marcados: revelarían, en la misma pregunta («¿Cómo es/se siente de joven/viejo?»), que desde la perspectiva del hablante se está presuponiendo que tal persona es joven/vieja, y la respuesta debería atender a tal adscripción previa: «Es muy joven/viejo»; «No, no es joven/viejo; es...».

Esta capacidad gradativa y acumulativa del adjetivo temporal mayor y su rentable funcionamiento como miembro no marcado de su serie tiene además un fuerte componente subjetivo (y social), pues, como explica Inmaculada Corrales Zumbado 1982 en su magno (y pionero) trabajo sobre el campo semántico edad en español, aunque la edad parece fácilmente objetivable como «periodo de la vida humana», todo lo que acarrea, todo lo que se asocia a cada uno de los periodos de la vida, convierte en valorativa (valoradora) la simple designación; por eso -explica- los sustantivos y adjetivos que forman parte de él son usados «en la evaluación de la edad» en cada etapa de la vida.

En la concepción de Corrales (que podemos aplicar íntegramente al adjetivo mayor, aunque no sea objeto específico de atención en su trabajo), el de la edad es un campo semántico subjetivo, de límites imprecisos entre los términos que lo integran, pues es la apreciación personal del usuario la que determina el alcance definitivo de cada término, la sustancia de su contenido. Hasta tal punto esto es así, que cualquier persona puede desplazar inconscientemente los límites de cada periodo conforme se acerca a la vejez.

¿Hay alguna duda de que nos comportamos realmente así? Así se explica que cuando somos niños nos parezcan «mayores» los jóvenes de treinta años, y los mismos nos parezcan «muy jóvenes» cuando tenemos sesenta, por ejemplo; así se explica que la niña de seis años se sienta «mayor» como para tomar coca-cola y sea la madre la que le pide que espere a ser un poco «más mayor»; así se entiende que una joven entrevistada en televisión se refiriera a sí misma como «soy una niña de veinticinco años que...», y que una mujer, adulta, insertara en una revista un anuncio de contacto en los siguientes términos:

(37) ¡Hola! Me llamo María. Soy soltera y tengo 55 años. Me gustaría conocer chicos de mi edad que vivan en Madrid, para salir y compartir aficiones (Mía, núm. 889, 22-28 sept. 2003).

\subsection{Más mayor en Hispanoamérica y en otras lenguas romances}

¿Se utiliza mayor con valor positivo y temporal en todo el ámbito del español y/o en otras lenguas romances? ¿Es más mayor un rasgo típico del español? Parece que sí. 
Pese a que «las fórmulas españolas de comparación analítica, formadas por un primer término adverbial (más..., menos..., tan...) y un segundo término conjuntivo ( que,como), no difieren en líneas generales de las usadas en las otras lenguas románicas»(Criado 1976, p. 76), la suerte de maior ha sido desigual en la Romania.

El adjetivo se ha conservado en francés, pero solo para «mayor de edad» (majeur se opone a mineur 'menor de edad'). En portugués, es solo aplicable a tamaño o dimensión física (Eu sou maior que você: "yo soy más alto/a que tú/usted»; no se puede/suele usar mais grande/pequenho en lugar de maior/menor; al contrario que en italiano, en que no se utiliza mayor para dimensiones físicas: sono piu grande). Tanto en italiano como en portugués y francés, el adjetivo usado para referirse a la edad es viejo: it. Il mio fratello è piu vecchio di me; port. Eu sou tan velha quanto você; fr. Mon frère plus vieux s'appelle Alain. En francés, se utiliza también, para indicar «de más edad», agé: Son père est beaucoup plus agé que le mien.

En el lenguaje infantil, en italiano y en francés se suele utilizar, curiosamente, grande en lugar de viejo: it. Mamma, io sono già grande, vero? Per quello vado a la scuola dei grandi; fr. Maman, je suis dejâ grande, n'est-cepas? Et je vais à l'école des grands. Gran es también el adjetivo utilizado en catalán para el campo temporal: molt gran ('muy mayor'), més gran ('mayor, más mayor'), Vaig al col.legi dels grans.

Y grande es también el adjetivo conservado para referirse a la edad y el paso del tiempo y sus efectos en parte de Hispanoamérica, y muy particularmente en Argentina y Uruguay, donde es común usarlo como en este ejemplo, en el que el actor argentino Federico Luppi contesta a una entrevista en televisión («CQC», 14-1-2001)

(38) -Después de tanto tiempo aquí [en España], ¿no habrá pensado en nacionalizarse y pasar a llamarse López?

-[Risas] ¡Estaría bueno!... No, lo que pasa es que ya estoy un poco grande para el trasplante...

Una búsqueda en el CREA (Corpus de Referencia del Español Actual, RAE, en línea) del sintagma más grande usado con sentido temporal, nos proporciona además ejemplos de Perú, Colombia, México y Paraguay (solo uno); no hemos encontrado, sin embargo, ninguno de Bolivia, Chile, Costa Rica, Cuba, Ecuador o El Salvador.

Parece evidente que ni mayor ni grande están generalizados con valor temporal en todo el ámbito del español. Mayor sí lo está en España, aunque grande y su opuesto, chico, se conocen también y se usan sobre todo en Andalucía. Mayor es también (re)conocido en toda Hispanoamérica, incluso en los países en que no se usa.

La conciencia de que más mayor es una incorrección parece, sin embargo, generalizada (o por lo menos mucho más extendida que en Es- 
paña) y su uso, generalmente corregido en la escuela, parece estar fuertemente estigmatizado. El rechazo no es, sin embargo, tan claro y rotundo para los ejemplos de "uso subjetivo" como Me siento muy mayor o Antonio está muy mayor para eso, o los de uso objetivo-valorativo como Antonio es ya muy mayor para eso. Seguramente por influjo de la escuela, tanto en España como en Hispanoamérica se percibía, y aún se percibe (y conviene, sin duda, hablar en términos de "percepción»), mucho más fácilmente la incorrección de más mayor que la de muy mayor, construcción que ni siquiera aparecía siempre condenada en las obras normativas, a pesar de revelar, como la comparativa, un uso positivo del adjetivo. Y seguramente alguna ley psicológica de percepción justifica también el hecho, significativo, de que sean muchos los hablantes (tanto en España como en Hispanoamérica) a los que la presencia del adverbio mucho baste para camuflar en el uso la posible incorrección de la construcción más mayor (que sí se le reconoce si aparece sola).

Lo cierto es que, si creemos a gramáticos y estudiosos, en Hispanoamérica, donde la tendencia a utilizar mayor con valor temporal parece inferior que en España, ha habido desde antiguo mayor inclinación a usar los comparativos sintéticos con marca comparativa, sobre todo mejor (más mejor) y peor (o pior: más pior), expresiones que Kany 1970 , p. 71, consideraba «relegadas a los iletrados en el uso popular y rústico tanto en España como en América», donde se consideran como formas positivas y que Criado 1976 adscribía al «habla vulgar». Solo unos cuantos años más tarde, Madero 1983 llega a la conclusión de que «en el habla culta de México (ciudad) son más frecuentes los comparativos orgánicos que los analíticos correspondientes». Madero reconoce además el uso de mayor cuando significa «adulto» y que, aunque no ha documentado más mayor ni muy mayor con el significado de 'adulto', 'grande' (es decir, como adjetivo positivo), los considera «posibles» y que además serían «normales» (p. 79). Pueden parecer datos contradictorios, y desde luego no contribuyen a aclarar el posible estatus «panhispánico» de nuestra construcción. Probablemente en Hispanoamérica sea mayor que en España la brecha entre lengua hablada (la que estudia Madero) y escrita, a la que se exige una mayor conciencia y fidelidad normativa. Del CREA hemos recogido estos tres ejemplos de lengua hablada, de los cuales el último (con el significado de «más importante», «más alto») se nos antoja muy improbable en el habla de España:

(39) La primera vez que me casé tenía 24 y fui madre el mismo año. Aunque tampoco era muy chica y ya estaba egresada de mi carrera, puedo decir que hoy veo la maternidad desde otra óptica. [...] Tuve muchos miedos. Entre ellos, por ejemplo, que voy a ser más mayor cuando esta guagua nazca... Pero hoy tengo la posibilidad de disfrutarla más. Ahora estoy mucho más consciente (Prensa, Chile, 12-5-97: Caras: «Margot Kahl anuncia su embarazo»). 
(40) [El papá de ella nos obligó a que nos casáramos] Entonces estuvimos viviendo, nació una niña que ahorita tiene cinco años ya, seguimos viviendo, y, bueno, hasta que ella conoció a un señor más mayor que yo, un señor maduro ya, que tenía ahí de todo y, bueno, sucesivamente se llegó el caso de separarnos, pues. De divorcio (Venezuela, oral cara a cara, [formalidad baja], CSCH-87, entrevista 19, 1987).

(41) Entonces vos tenés, como te decía, tenés los chicos desde siete años hasta adultos. Y además tenés una gama amplia de grupos sociales porque vienen chicos de barrios marginales, de algunas ciudades aledañas y también chicos de un nivel sociocultural un poco más mayor, ¿verdad? (Paraguay, oral cara a cara [formalidad baja], encuesta 65, María Victoria Eihiesecke, 1993).

\section{DE LA CONDENA A LA ABSOLUCiÓN NORMATIVA}

Visto desde la gramática y desde la norma lingüística, la verdad es que nada presagiaba, aparentemente, el cambio efectivo que la aparición del Diccionario panhispánico de dudas (2005) supuso respecto de más mayor.

Aunque la mayoría de las obras normativas condenaban abiertamente (con pocas explicaciones o ninguna) la construcción, calificándola de «popular»(Seco 1998, s. v.), «vulgarismo» (Casado 1988, p. 53; Martínez de Sousa 1996, s. v.; Aroca 1997, s. v.; Seco y Hernández 1999, s. v.; De la Banda 2000, s. v.; etc.), «pleonasmo» (Diccionario Sopena de dudas 1981, s. v.), «redundancia inelegante»(Cascón 1999, p. 234), «solecismo»(Seco 1961, s. v.), «agramatical» (De Lucas 1995, s. v.), «no correcta» (Gómez Torrego 1989 y 1998)..., algunas entre ellas daban pistas de la contradicción entre la preceptiva y el uso. Señalaban, por ejemplo, que mayor no podía usarse con muy o con más y, a continuación afirmaban, por ejemplo, «sin valor comparativo cuando significa viejo» (Seco 1961), o «cuando mayor se refiere al campo semántico de la edad no tiene adjetivo en grado positivo en español peninsular»y puede, por tanto, utilizarse combinado con la marca de grado comparativo: Tu hijo es tan mayor como el mío (Gómez Torrego 1998, p. 53); o hacían notar que si se utilizan más mayor y muy mayor, «quiere decir que mayor no se siente como comparativo» (De Lucas 1995); o consideraban la construcción "posible [...] en relación a la edad» (Romera y otros 1994, p. 103); o aceptaban que «si se refiere a edad, se puede usar muy mayor» (Libro de estilo de Abc 2001, p. 106)... En toda la bibliografía consultada solo se describe como correcta, sin matices, en Quilis y otros 2000, p. 158: «La excepción de esta norma es el adjetivo mayor, que puede combinarse con tan y más cuando expresa edad (Como te hagas más mayor, perderás encanto; Soy tan mayor como tú, no te hagas el viejo)». 
Las gramáticas «descriptivas», por su parte, parecían aceptar tácita e implícitamente (explícitamente a veces) el valor comparativo de los adjetivos orgánicos, sin entrar, como es lógico, en su posible (in)corrección y, en general, sin ocuparse del fenómeno de más mayor. Alguna como la de Alarcos 1994, p. 85, muestra también, en un breve y ambiguo comentario, algún rastro de esa contradicción entre la categoría / función lingüística de mayor y la realidad de su uso más extendido: «Aunque por su origen latino [mejor, peor, mayor y menor] se llaman comparativos sintéticos, sus funciones son las mismas de los demás adjetivos» (¿Quiere esto decir que se comportan igual, como positivos -es decir, como «los demás adjetivos»-?).

La construcción más mayor iba, así, cumpliendo su destino natural de «excepción» gramatical dentro de la norma, catalogada como error (incorrección, vulgarismo, etc.).

Sin embargo, aunque ni gramáticas ni obras normativas lo reconocieran, la lexicalización de mayor como adjetivo positivo había seguido el camino de la analogía, que es «una de las leyes más fuertes y persistentes en el cambio y la variación lingüísticos» (Moreno Cabrera 2002, p. 24) y «una de las manifestaciones más claras de uno de los principios básicos del funcionamiento de las lenguas: el principio de la automatización retroactiva», que exige al hablante la emisión más rápida posible que sea interpretable (Moreno Cabrera 2002, p. 30). Tal lexicalización podemos considerarla doblemente excepcional si tenemos en cuenta además que se ha producido en un caso de supletivismo, que representa -en palabras de J. Elvira 1998, p. 136- «el caso más extremo de resistencia a la nivelación analógica». Y seguramente tal cambio lingüístico, como afirma Coseriu 1978, p. 78 que suele ocurrir, tuvo su origen «en el habla, en el diálogo», donde el hablante, condicionado por la inmediatez y la necesidad de adecuarse contextualmente tanto a su destinatario como a los requerimientos (diversos) de su acto comunicativo particular, se ve abocado a la improvisación formal, la fluidez elocutiva, la expresión del sentido por aproximación y, en general, los imperativos de la comunicabilidad (cf. Vigara 1992 y 1996). En tales condiciones, el hablante busca (y encuentra) el modo de decir lo que quiere decir, aunque sea "por aproximación». Y podemos considerar que si muchas personas encuentran muchas veces ese modo de decir lo que quieren decir (en la construcción más mayor, p. ej.) y sus interlocutores lo interpretan espontánea y automáticamente de forma «adecuada», es que se han creado o se están creando las condiciones para el cambio (lingüístico), para la consolidación de la novedad y su incorporación al sistema de la lengua.

Y lo cierto es que si nos preguntamos acerca de las condiciones discursivas que propician la aparición y consolidación de la construcción más mayor y acerca de su implicación social (cf. Bosque 1991, pp. 42 y ss.), 
encontraremos buenas razones para justificarla (justificar su uso y su amnistía normativa), que parecen hacer bueno aquello de que «la lengua no funciona para y por los gramáticos, sino para y por el pueblo» (Coseriu 1992, p. 100):

- ¿Qué clase de hablantes la utiliza (sobre todo en España)? Cualquiera, todos pueden y suelen utilizarla: niños y mayores, mujeres y hombres, cultos e iletrados, del norte y el sur y el centro y el este y el oeste...

- ¿Qué revela de ellos? Que la mayoría no tiene conciencia de la posible incorrección o inelegancia de su uso.

- ¿Pertenece a un solo tipo de registro/género/habla..., se asocia exclusivamente a ciertas situaciones específicas? No. Lo peculiar de más mayor es que se utiliza solo en relación con la edad, el paso del tiempo y sus efectos; pero puede aparecer en cualquier registro y casi en cualquier contexto sintáctico, situacional, discursivo o presuposicional; es fácil documentar ejemplos tanto en «textos» orales como escritos u oralizados, informales o formales...

- ¿Quiénes la rechazan? En general, no los individuos de los «estratos superiores» ni los «cultos» (y cabría preguntarse aquí a qué llamamos «estratos superiores» y quiénes son las personas «cultas»), sino sobre todo los lingüistas, los profesores, las personas que son o se sienten responsables del buen uso de la lengua o de su enseñanza correcta.

- ¿Estigmatiza su uso al hablante? Obviamente, no, puesto que no es rasgo «limitado» ni suficientemente consciente en el uso del hablante común.

Todo esto, sin embargo, ha sido así durante mucho tiempo y no ha resultado, hasta la llegada del Diccionario panhispánico (octubre 2005), suficiente para que el cambio en el juicio normativo se produjera. $\mathrm{Y}$ ahora que se ha producido, para sorpresa de casi todos, son todavía muchas las personas renuentes a aceptarlo o dispuestas a olvidar que les «suena mal». Para muchos, tan difícil es aceptar que mayor funciona como adjetivo positivo como aceptar el cambio normativo en la consideración de más mayor (que se fundamenta precisamente en su «funcionamiento», además de en el uso «culto»).

Esto nos lleva, inevitablemente, de vuelta al planteamiento de si el «juicio lingüístico» debe ser prescriptivo o estrictamente descriptivo y de si la descripción lingüística («científica») que podamos hacer (como se ha hecho aquí, por ejemplo, respecto del funcionamiento de más mayor) puede y/o debe influir o no en el juicio normativo y en la consideración de los hablantes. ¿Dónde reside la norma? ¿Quiénes son sus depositarios? ¿Quién tiene autoridad sobre ella? ¿Nos corresponde a los lingüistas esa autoridad, o deberíamos más bien dedicarnos a hacer «ciencia lingüística» y delegar la prescripción en otros? ¿A quién se le reconoce, y en qué ámbito, esa autoridad? 
De la respuesta que diéramos a todas estas preguntas dependería, previsiblemente, la existencia de construcciones como la que nos ocupa y su consideración social. Pero lo cierto es que, normalmente, no solemos hacérnoslas, quizá porque pensamos (aunque sea solo intuitivamente) que no sabríamos responderlas. Que no tienen una respuesta que dé satisfacción a todos, que sea suficientemente clara e incuestionable. ¿Cuál es exactamente la norma «culta» y qué «licencias» puedo permitirme o no en el uso del lenguaje o en su consideración si quiero seguir siendo una persona «culta»? En una entrevista hecha al lingüista y académico José Manuel Blecua (R), ahora director de la RAE, a raíz del II Congreso de la Lengua Española (Valladolid, 2001) y la presentación de la última edición del diccionario académico se aludía a todo esto:

R. [Y] se ha aceptado que hay una norma abstracta muy flexible, que es la norma culta, la lengua estándar, la que se puede entender en todos lados.

P. ¿Y quién la determina?

R. Ahora hay que investigar eso, hay que saber quién hace la norma culta. Creo que es la de los escritores prestigiosos, los textos científicos y, sobre todo, los medios. Los modelos más imitables, sobre todo la radio y la televisión.

Y, en último término, ¿quién decide quiénes son los escritores prestigiosos, qué textos científicos pueden servirnos como modelo y cuáles no, o en qué medida son imitables prensa, radio y televisión (en la lengua hablada o en la escrita)?

\section{A MODO DE CONCLUSIÓN}

Hasta la llegada del Diccionario panhispánico, la construcción más mayor era un ejemplo representativo de cómo se categorizan ciertas «excepciones» gramaticales y de cómo, una vez categorizadas, la tradición, la norma y el uso influyen poco o nada en su consideración (e incluso en su existencia).

Clasificado el adjetivo mayor como comparativo (sintético, morfológico, orgánico...) con la ayuda del latín, de los diccionarios de español y sus etimologías, el juicio normativo se aplica a la corrección de más mayor, comparación (redundantemente comparada) de grande (que se documenta en romance), sin tener en cuenta el significado temporal de la expresión, con el que se generaliza en España (donde raramente se utiliza el adjetivo para significar «tamaño, volumen») y se conoce (y se usa en parte) en Hispanoamérica. Durante mucho tiempo, (re)conocer que tal construcción tiene sus raíces ya en latín, está presente «en todas las épocas del idioma» y su uso es muy abundante y está bastante generalizado no ha influido apenas en su consideración. 
De hecho, aunque los diccionarios recogen la sustantivación mayor (de edad) y mayores 'ancianos', no reflejan -salvo excepciones- la lexicalización del adjetivo como positivo (que afectaría, lógicamente, también a tan mayor y muy mayor). El juicio normativo parece, así, convertirse en prejuicio, y la construcción se condena «automáticamente»como incorrecta, agramatical o vulgar, tanto en la escuela como entre los autores normativos y los «responsables» del buen uso del lenguaje, aun cuando el contraste con la realidad del uso obliga a los más conscientes a caer en contradicción en sus explicaciones.

La construcción temporal más mayor ha seguido y sigue, no obstante, su curso, pese a la condena normativa, y al margen del resto de los adjetivos comparativos heredados del latín (menor, mejor y peor), que conservan su función -salvo excepciones también-y su significado original (con la excepción de la lexicalización de menor [de edad]). La amnistía normativa oficial que el Diccionario panhispánico de dudas concede, inesperadamente, a la construcción añade a su excepcionalidad gramatical (y semántica) una excepcionalidad más (que no se ha producido con ningún otro adjetivo de su paradigma) y, sobre todo, le concede un nuevo estatus por el que, previsiblemente, podremos pronto describir como un hecho de lengua lo que no era hasta ahora más que un hecho (irrefutable) de discurso.

\section{REFERENCIAS BIBLIOGRÁFICAS}

Alarcos, E. (1994): Gramática de la lengua española, Madrid, RAE-Espasa-Calpe.

Aroca, J. (1997): Diccionario de atentados contra el idioma español, s. d., Palabras Mayores.

BANDA, M. de la (2000): Escafurcios y palabros. Diccionario de abuso de la lengua castellana, Madrid, Temas de Hoy.

Bello, A. (1847-1860) (1981): Gramática de la lengua castellana. Destinada al uso de los americanos (con las anotaciones de Rufino José Cuervo, 1898) (edic. crítica de Ramón Trujillo), Tenerife, Instituto Universitario de Lingüística Andrés Bello-Cabildo Insular de Tenerife.

Bosque, I. (1985): «Usos figurados de los adjetivos que denotan dimensiones físicas», Philologica hispaniensia in honorem Manuel Alvar, vol. II, Lingüistica, Madrid, Gredos, pp. 63-80.

- (1991): «Consideraciones sobre la enseñanza de la gramática», en Terrón González, J. y Blázquez Entonado, F. (coords.), I Jornadas de metodología y didáctica de la lengua y literatura españolas, Cáceres, ICE-Universidad de Extremadura, pp. 33-62.

Calvo, J. (1986): Adjetivos puros. Estructura léxica y topología, Valencia, Universidad de Valencia.

CASADO, M. (1988): El castellano actual. Usos y normas, Pamplona, Eunsa.

CAscón, E. (1999): Manual del buen uso del español, Madrid, Castalia. 
Corrales Zumbado, I. (1982): El campo semántico 'edad'en español, La Laguna, Secretariado de Publicaciones de la Universidad de La Laguna.

Coseriu, E. (1978): Sincronía, diacronía e historia. El problema del cambio lingüistico, 3르 ed., Madrid, Gredos (orig. 1958).

- (1992): Competencia lingüistica. Elementos de la teoría del hablar, Madrid, Gredos.

Covarrubias, S. de (1943): Tesoro de la lengua castellana o española, según la impresión de 1611, con las adiciones de Benito Remigio Noyden publicadas en la de 1674 (edic. preparada por Martín de Riquer), Barcelona, Horta.

Criado de VAL, M. (1976): Gramática española y comentario de textos, Madrid, S.A.E.T.A. (1 ${ }^{\underline{a}}$ ed. 1958).

Diccionario Sopena de dudas y dificultades del idioma (1981): Barcelona, Ramón Sopena.

Dixon, R. M. W. (1977): «Where have all the adjectives gone?», Studies in Language 1, 1, pp. 19-80.

ELVIRA, J. (1998): El cambio analógico, Madrid, Gredos

Gómez, L. (1989): Manual de español correcto, vol. II, Morfología y sintaxis, estilo, léxico, Madrid, Arco/Libros.

- (1998): Gramática didáctica del español, 4ª ed., Madrid, SM.

KAnY, Ch. E. (1969): Sintaxis hispanoamericana, Madrid, Gredos (orig. 1945).

Kerbrat-Orecchini, C. (1994): La subjetividad en el lenguaje, Buenos Aires, Hachette.

LAMÍQUIZ, V. (1991): La cuantificación lingüistica y los cuantificadores, Madrid, UNED.

LóPEz, Á. (1998): «El adjetivo», en López García, A., Gramática del español, vol. III, Las partes de la oración, Madrid, Arco/Libros, pp. 147-172.

LuCAS, C. de (1995): Diccionario de dudas, Madrid, EDAF.

MAdero, M. (1983): «La gradación del adjetivo en el habla culta de la ciudad de México», Anuario de Letras 21, pp. 71-118.

Martínez, J. (1996): Diccionario de usos y dudas del español actual, Barcelona, Biblograf.

Moreno Cabrera, J. C. (2002): «El motor de la economía lingüística: de la ley del menor esfuerzo al principio de la automatización retroactiva», RSEL 32, 1, pp. 1-32.

Quilis, A. y otros (2003): Lengua española. Curso de acceso, Madrid, Centro de Estudios Ramón Areces.

ReAl ACAdEMIa EsPañola: NTLLE (Nuevo Tesoro Lexicográfico de la Lengua Española), banco de datos accesible en red: <www.rae.es>

- (1734): Autoridades. Compuesto por la Real Academia Española. Tomo quarto. Que contiene las letras G.H.I.J.K.L.M.N. Madrid, Imprenta de la Real Academia Española, por los herederos de Francisco del Hierro

- (1780): Diccionario de la lengua castellana, Madrid, Joaquín Ibarra.

- (1803): Diccionario de la lengua castellana, 4⿳a ed., Madrid, Viuda de Ibarra.

- (1852): Diccionario de la lengua castellana, 10 $\mathrm{a}$ ed., Madrid, Imprenta Nacional. 


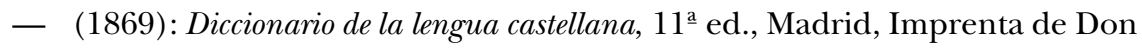
Manuel Rivadeneyra.

- (1984): Diccionario de la lengua española, 20 ed., Vol. II, Madrid, EspasaCalpe.

- (1984): Diccionario manual e ilustrado de la lengua española, $3^{\mathbf{a}}$ ed., Vol. III, Madrid, Espasa-Calpe.

RAE / Asoc. Academias de la Lengua Española (2005): Diccionario panhispánico de dudas [DPD], Madrid, Santillana (Accesible en red).

ROMERA, J. y otros (1994): Manual de estilo, Madrid, UNED.

SECO, M. (1961): Diccionario de dudas y dificultades de la lengua española, Madrid, Aguilar.

- (1998): Diccionario de dudas y dificultades de la lengua española, 10ª ed., Madrid, Espasa-Calpe.

- y Hernández, E. (1999): Guía práctica del español actual. Diccionario breve de dudas y dificultades, Madrid, Espasa-Calpe.

Vigara, A. M. (1992): Morfosintaxis del español coloquial. Esbozo estilístico, Madrid, Gredos.

- (1996): «Español coloquial: expresión del sentido por aproximación», en Kotschi, Th., Oesterreicher, W. y Zimmermann, K. (eds.), El español hablado y la cultura oral en España e Hispanoamérica, Frankfurt/Madrid, Vervuert/Iberoamericana, pp. 15-44.

- y Consejo de Redacción De Abc (2001): Libro de estilo de Abc, Barcelona, Ariel. 
